
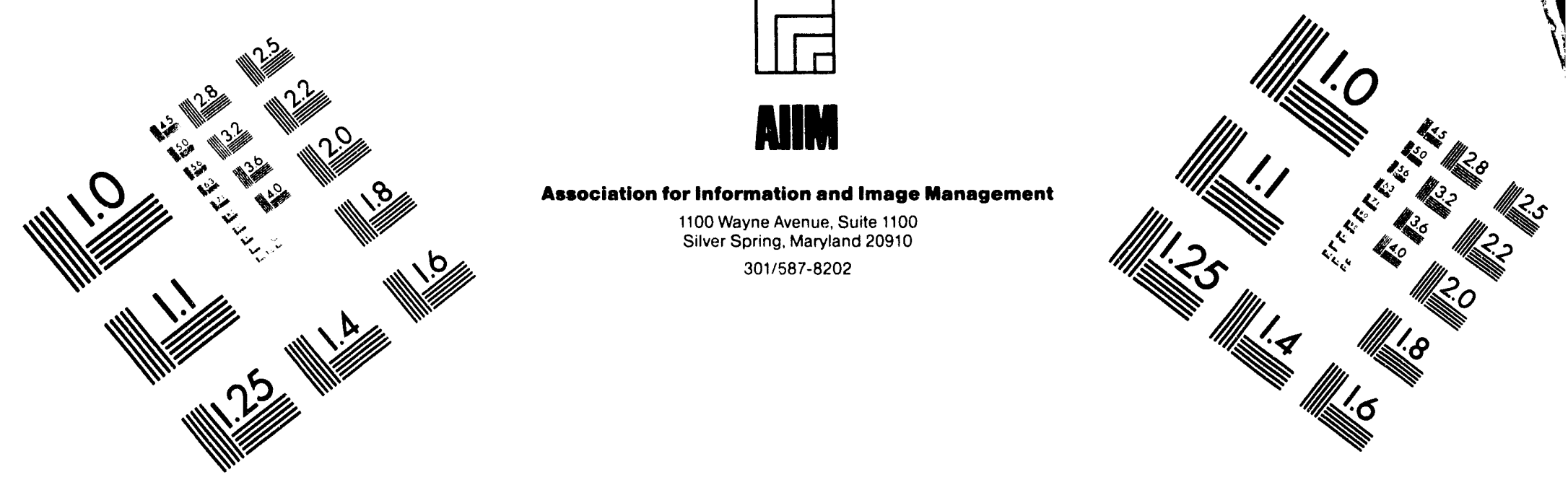

\title{
Centimeter
}

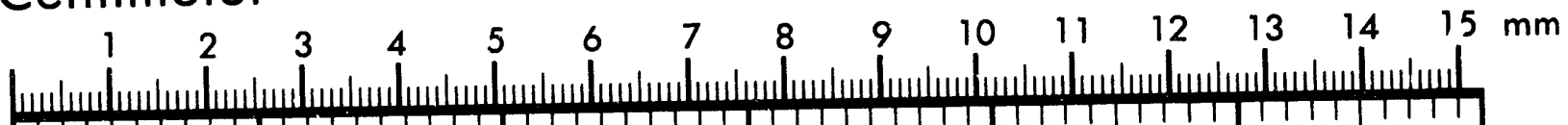

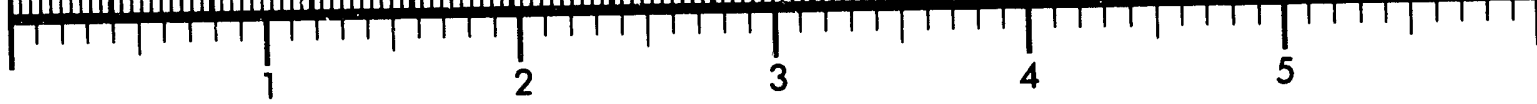

Inches
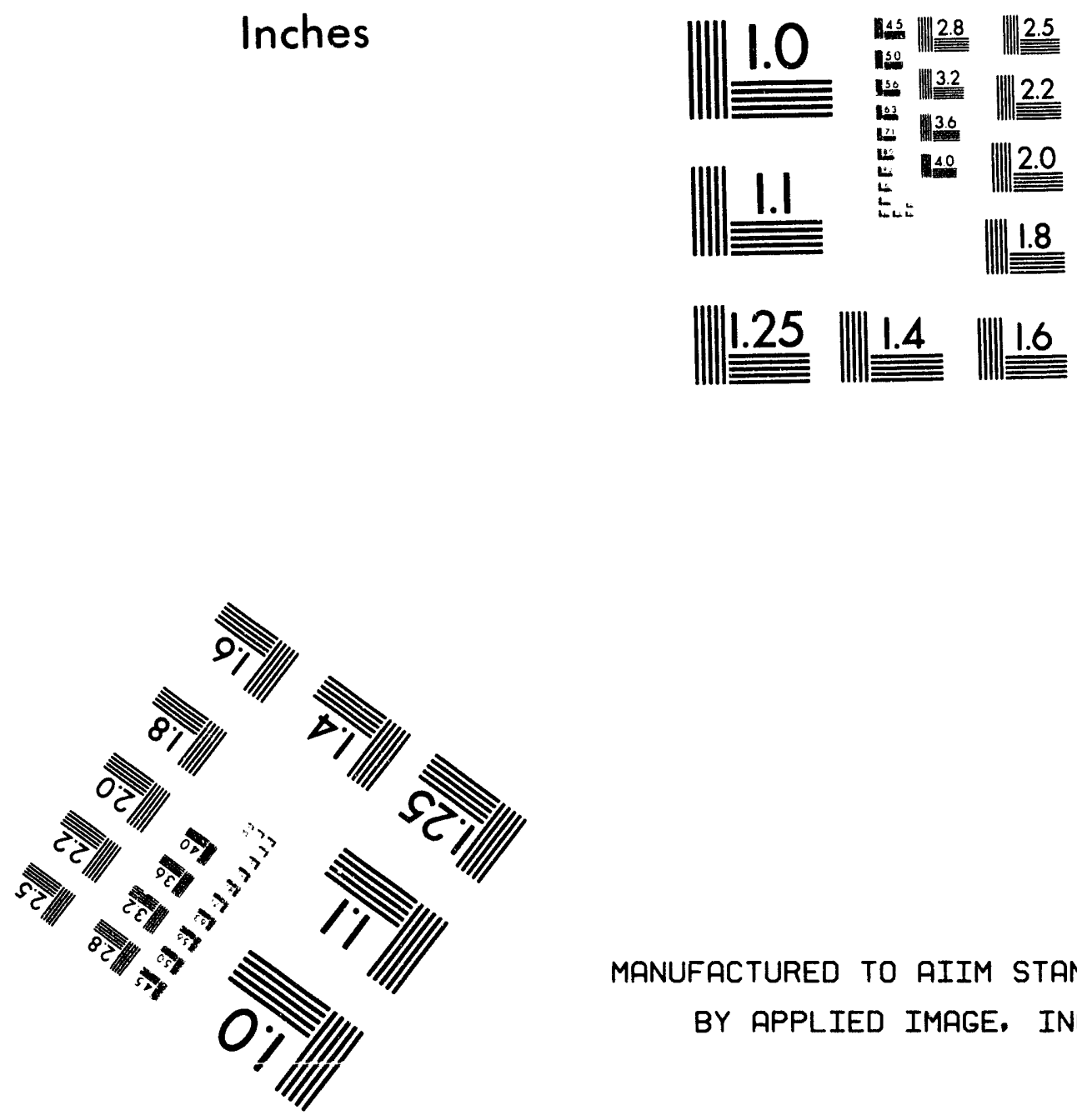

MANUFACTURED TO AIIM STANDARDS

BY APPLIED IMAGE, INC.

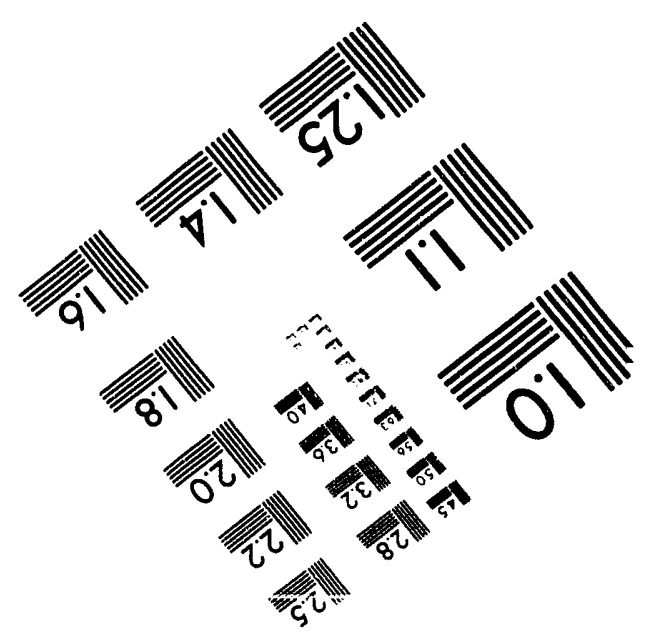



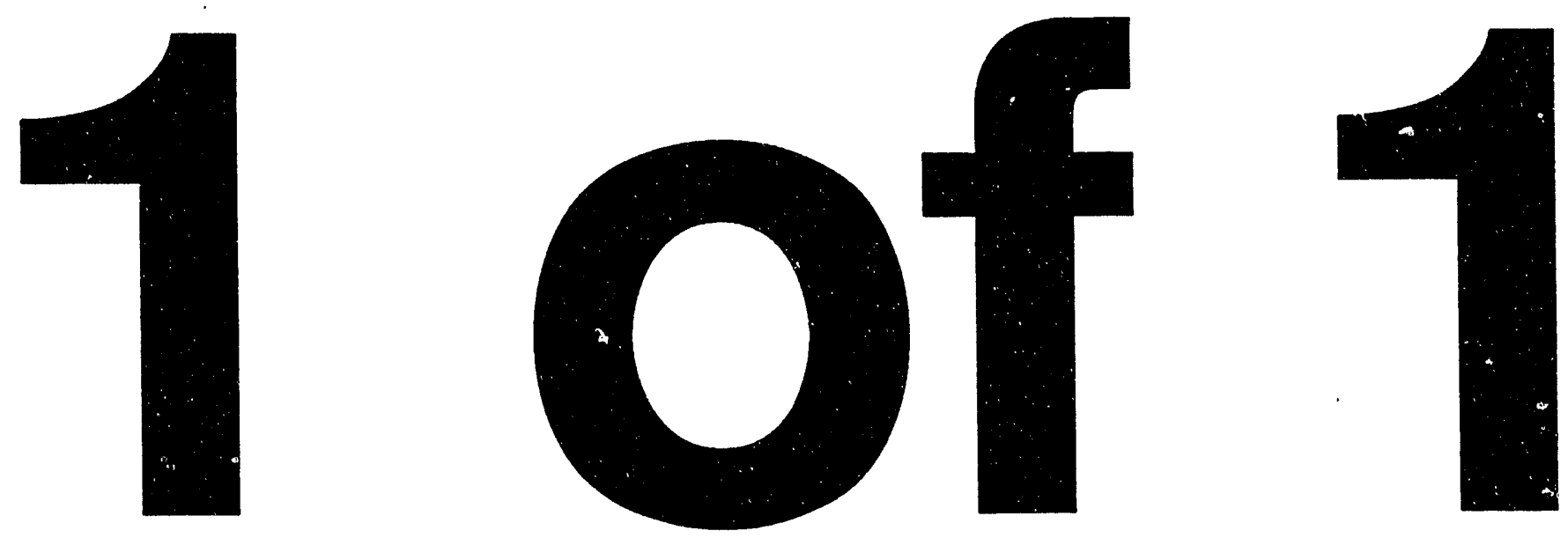


\section{THE DUAL ROLE OF OXYGEN FUNCTIONS IN COAL PRETREATMENT AND} LIQUEFACTION: CROSSLINKING AND CLEAVAGE REACTIONS

Seventh Quarterly Report

\#523085

For the Period

September 30, 1992 to December 31, 1992

MICHAEL A. SERIO

ERIK KROO

SYLVIE CHARPENAY

PETER R. SOLOMON

with contributions by:

RIPUDAMAN MALHOTRA (SRI)

DONALD MCMILLEN (SRI)

Work Performed Under Contract No. DE-AC22-91-PC91026

Arun Bose, Project Manager

by

ADVANCED FUEL RESEARCH, INC.

87 Church Street

East Hartford, CT 06108

(203) 528-9806

"US/DOE patent clearance is not required prior to the publication of this document."

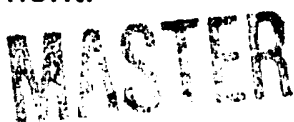


THE DUAL ROLE OF OXYGEN FUNCTIONS IN COAL PRETREATMENT AND LIQUEFACTION: CROSSLINKING AND CLEAVAGE REACTIONS

\section{SEVENTH QUARTERLY REPORT - CONTRACT NO. DE-AC22-91-PC91026}

\section{TABLE OF CONTENTS}

Disclaimer $\ldots \ldots \ldots \ldots \ldots \ldots \ldots \ldots \ldots \ldots \ldots \ldots \ldots \ldots \ldots \ldots \ldots \ldots \ldots \ldots \ldots \ldots$

Abstract $\ldots \ldots \ldots \ldots \ldots \ldots \ldots \ldots \ldots \ldots \ldots \ldots \ldots \ldots \ldots \ldots \ldots \ldots \ldots \ldots$ ii

I. INTRODUCTION $\ldots \ldots \ldots \ldots \ldots \ldots \ldots \ldots \ldots \ldots \ldots \ldots \ldots \ldots \ldots \ldots \ldots \ldots$

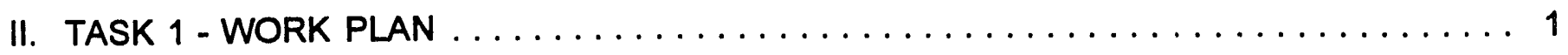

III. TASK 2 - STUDIES WITH COALS AND MODIFIED COALS . . . . . . . . . . . 1

IV. TASK 3 - STUDIES WITH POLYMERIC MODEL SYSTEMS $\ldots \ldots \ldots \ldots \ldots \ldots$

V. TASK 4 - DATA INTEGRATION AND REPORTING $\ldots \ldots \ldots \ldots \ldots \ldots \ldots$

VI. PLANS FOR EIGHTH QUARTER $\ldots \ldots \ldots \ldots \ldots \ldots \ldots \ldots \ldots \ldots \ldots \ldots \ldots$

References $\ldots \ldots \ldots \ldots \ldots \ldots \ldots \ldots \ldots \ldots \ldots \ldots \ldots \ldots \ldots \ldots \ldots \ldots \ldots \ldots$

APPENDIX A - "The Effects of Moisture and Cations on Liquefaction of Low Rank Coals" - paper

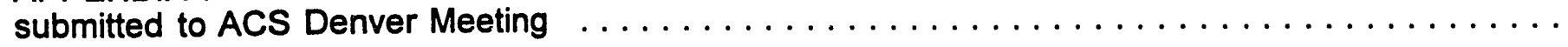
APPENDIX B - Abstracts submitted to International Conference on Coal Science

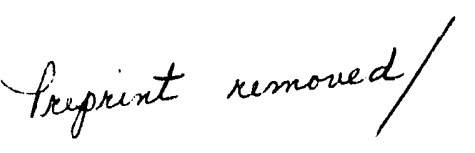




\section{DISCLAIMER}

This report was prepared as an account of work sponsored by the United States Government. Neither the United States nor the United States Department of Energy, nor any of their employees, makes any warranty, express or implied, or assumes any legal liability or responsibility for the accuracy, completeness, or usefulness of any information, apparatus, product, or process disclosed, or represents that its use would not infringe privately owned rights. Reference herein to any specific comme, cial product, process, or service by trade name, mark, manufacturer, or otherwise, does not necessarily constitute or imply its endorsement, recommendation, or favoring by the United States Government or any agency thereof. The views and opinion of authors expressed herein do not necessarily state or reflect those of the United States Government or any agency thereof. 


\begin{abstract}
The work during the past quarter under Task 2 has focused on the investigation of FT-IR methods for measuring carboxyl and phenolic functions. Fourier transform infrared (FT-IR) spectra of coal contain a wealth of information that can be utilized in the development of quantitative analysis routines based on least squares curvefitting. In this work, we have modified the technique of Solomon et al. by allowing the curvefitting algorithm to determine the positions of those bands prone to shifting. Reduced spectral ranges were used in order to accommodate the increased number of parameters to be determined. The initial parameters for the curvefitting algorithm (number of bands, band assignments) were set using data available in the literature. Because of the importance of the carboxylate groups in retrogressive reactions, recent efforts have focused on the $C=O$ stretching region. Raw and modified coal samples (acid washed, demineralized, and cation exchanged) were analyzed in order to validate the proposed band assignments in the $C=O$ stretching region. This parameter set differentiates free carbonyl (B2) and hydrogen-bonded carbonyl (B4) from carboxylic acid carbonyl (B3) and carboxylate (B7). One test of these assignments, which are based on literature data, is to plot B3 versus B7. This should be linear, assuming that the sum of the free carboxyl and carboxylate groups is constant and that the intensity of the overlapped aromatic ring band in B7 is also constant. This relationship was found to hold for a set of raw, acid washed, and acid washed/cation-exchanged Zap coals.
\end{abstract}

The work under Task 3 has involved (1) completion of the synthesis of the -C-C-O- linked, methoxy substituted lignin-network polymer, $-\left[\mathrm{C}_{6} \mathrm{H}_{3}(\mathrm{O}-\mathrm{OMe})-\mathrm{O}-\mathrm{CH}_{2} \mathrm{CH}_{2}\right]_{7}-$ polymer,

(2) Analysis of the polymer via depolymerization under pyrolysis-FIMS (Py-FIMS) conditions, and (3) testing of several routes to selective cleavage of the O-Methyl bond so that the relative crosslinking tendencies of the methylated and unmethylated versions of the polymer colid be determined.

Work was completed on the ACS Denver paper, titled "The Effects of Moisture and Cations on liquefaction of Low Rank Coals." In addition, three abstracts were prepared for the International Conference on Coal Science (Banff, Alberta, CANADA, September 12-17, 1993) based on the work done under this project. The first is titled "The Role of Cations in Retrogressive Reactions During Pyrolysis and Liquefaction," which concerns the work done on coals and modified coals. The second is titled "Application of a Spectral Deconvolution Technique to Coal FT-IR Spectra," which concerns the use of FT-IR methods for measurement of carboxyl and hydroxyl functions. The third paper is titled "Pyrolysis Pathways and Kinetics of Polymeric Models for Low-Rank Coals" which focuses on the thermal decomposition chemistry of the $\beta$-ether-linked lignin model polymers. 


\section{INTRODUCTION}

The overall objective of this project is to elucidate and model the dual role of oxygen functions in thermal pretreatment and liquefaction of low rank coals through the application of analytical techniques and theoretical models. The project will be an integrated study of model polymers representative of coal structures, raw coals of primarily low rank, and selectively modified coals in order to provide specific information relevant to the reactions of real coals. The investigations will include liquefaction experiments in microautoclave reactors along with extensive analysis of intermediate solid, liquid and gaseous products. Attempts will be made to incorporate the results of experiments on the different systems into a liquefaction model.

\section{TASK I - WORK PLAN}

This task is complete.

\section{TASK 2 - STIIDIES WITH COALS AND MODIFIED COALS}

The work during the past quarter under Task 2 has focused on the investigation of FT-IR methods for measuring carboxyl and phenolic functions. Fourier transform infrared (FT-IR) spectra of coal contain a wealth of information that can be utilized in the development of quantitative analysis routines based on least squares curvefitting. However, since the exact composition of the coal is not known, the selection of parameters, such as the number, position, and width of the bands, is not straightforward. The application of Fourier self-deconvolution, maximum likelihood restoration, and the calculation of derivative spectra has been shown capable of narrowing bandwidths in order to facilitate the selection of these parameters $(1,2)$. However, these techniques provide poor results for spectra with highly overlapped bands, baseline errors or high noise levels $(1,2)$. Although coal spectra typically exhibit these shortcomings, some of these approaches have been utilized $(3,4)$. As an alternative to the approach mentioned above, Solomon et al. $(5,6)$ defined a set of 24 Gaussian bands with fixed positions and widths that could reproduce coal spectra within the experimental error. Although good correlations were observed for coal samples of different rank, the use of fixed band positions prevents the observation of band shifts induced by changing interand intramolecular interactions in the coal structure.

In this work, we have modified the technique of Solomon et al. $(5,6)$ by allowing the curvefitting algorithm to determine the positions of those bands prone to shifting. Reduced spectral ranges were used in order to accommodate the increased number of parameters to be determined. The initial parameters for the curvefitting algorithm (number of bands, band assignments) were set using data available in the literature. The key to this approach is that known modifications were made to the hydroxyl and carboxyl functional groups within the coal structure in order to test the curvefitting 
results. Because of the importance of the carboxylate groups in retrogressive reactions, recent efforts have focused on the $\mathrm{C}=\mathrm{O}$ stretching region. Raw and modified coal samples (acid washed, demineralized, and cation exchanged) were analyzed in order to validate the proposed band assignments in the $\mathrm{C}=0$ stretching region given in Table III-1. This parameter set differentiates free carbonyl (B2) and hydrogen-bonded carbonyl (B4) from carboxylic acid carbonyl (B3) and carboxylate (B7). One test of these assignments, which are based on literature data, is to plot B3 versus $B 7$. This should be linear, assuming that the sum of the free carboxyl and carboxylate groups is constant and that the intensity of the overlapped aromatic ring band in B7 is also constant. This relationship was found to hold for a set of raw, acid washed, and acid washed/cation-exchanged Zap coals, as shown in Figure III-1.

\begin{tabular}{|c|c|c||}
\hline band \# & position & Assignment \\
\hline B1 & $* 1772$ & \\
\hline B2 & $* 1738$ & C=O \\
\hline B3 & 1708 & COOH \\
\hline B4 & 1690 & C=O..H \\
\hline B5 & 1650 & broad water band \\
\hline B6 & 1600 & arom.str. 1 \\
\hline B7 & $* 1575$ & COO-, arom.str. 2 \\
\hline B8 & 1508 & \\
\hline B9 & 1454 & \\
\hline
\end{tabular}

Table III-1. Band positions and assignments used for input parameters for the $\mathrm{C}=\mathrm{O}$ stretching region ( ${ }^{*}$ indicates fixed band position)

Acid washing the raw Zap samples results in an increase in the $\mathrm{COOH} / \mathrm{COO}$-band intensity ratio. Cation exchanging the acid washed samples returns the $\mathrm{COOH} / \mathrm{COO}$-ratio to approximately the same value observed for the raw coal. This is demonstrated more quantitatively in Figure III-2. Coal samples with a relatively wide range of $\mathrm{COOH} / \mathrm{COO}$-ratios were prepared by cation exchanging demineralized coal samples using different cations under varying conditions (7). Clearly a linear relationship between the intensities of the carboxylic acid band and the carboxylate band is demoristrated. The difference between the raw (Figure III-1) and demineralized (Figure III2) coals possibly reflects the interaction of mineral matter with the carboxyl group. 


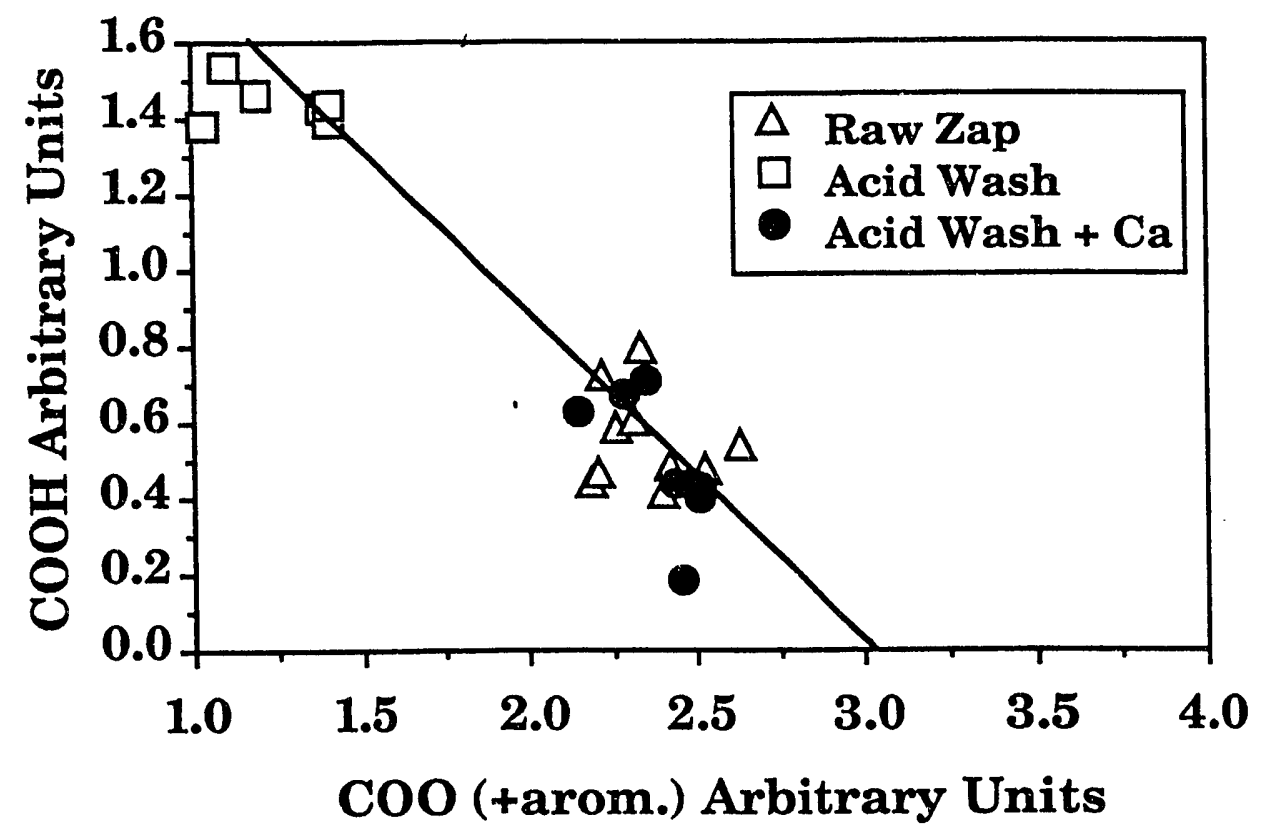

Figure III-1. Relationship of Carboxylic Acid and Carboxylate Band Intensities for Raw, Acid Washed, and Acid Washed-Cation Exchanged Zap Coals.

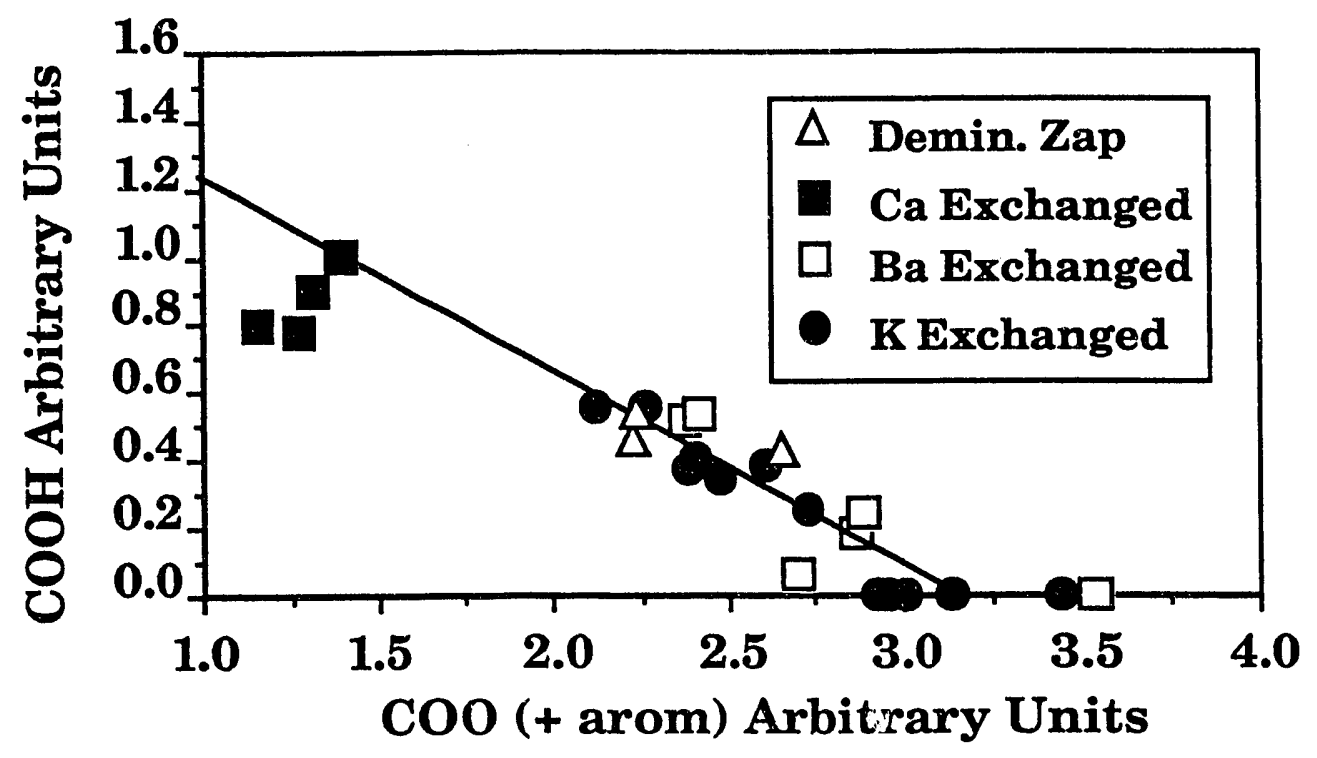

Figure III-2. Relationship of Carboxylic Acid and Carboxylate Band Intensities for Demineralized and Demineralized-Cation Exchanged Zap Coals. 


\section{TASK 3 - STUDIES WITH POLYMERIC MODEL SYSTEMS}

\section{INTRODUCTION}

It has become increasingly clear in recent years not only that retrograde reactions substantially hinder the liquefaction of low-rank coals, but also that oxygen functional groups in the coal structure are major actors in these retrograde reactions. The evidence connecting oxygen groups to the formation of new, strong bonds, though convincing, is largely phenomenological in nature rather than mechanistic. Thus we know that crosslinking is correlated with the evolution of $\mathrm{CO}_{2}$ and $\mathrm{H}_{2} \mathrm{O}$ and therefore that carboxyl and/or phenolic groups are involved, but we do not know exactly how or why. In order to know how to best mitigate the retrograde reactions it is necessary to better understand their mechanisms -i.e., to know what factors promote and inhibit these reactions.

Task 3 complements the other tasks in this project in that it seeks to help understand why certain pretreatments tested with real coals are found to mitigate retrograde reaction and thus help lead to improved or different pretreatments. The approach to achieving this goal is to prepare and study the behavior of polymeric coal models under liquefaction conditions. This will provide us not only with starting materials and products that are both better known than is possible with real coals, but also with structures and reaction conditions that are more relevant to the liquefaction of real coals than are the typical "model compound" studies. Polymeric models should be more relevant to coals particularly with respect to mass-transport factors that come into play with insoluble starting materials. The difficulty is not to make them too relevant: If the polymers are too much like real coals, both they and their products will be unanalyzable. Therefore, judicious choices are necessary in the attempt to focus on those oxygen-containing structures that are likely to be key to retrograde reactions in low-rank coals.

i he first objective of Task 3 is to prepare polymer models having phenolic, carboxylic, and/or aryl ether groups considered to be important in low rank coals. There are two aspects to the choice of appropriate polymers: the choice of the polymeric backbone and the choice of the functional groups. One approach is to focus on the chemistry of the chosen functional groups in a polymeric matrix by selecting a polymer backbone that is itself not subject to cleavage under the reaction conditions (e.g., polyaryls). The other approach is to choose a backbone that is presumed to be coal-relevant and seek to understand its behavior first without, and then with, appended, relevant oxygen functional groups. As discussed in the Annual Topical Report, we have worked on both of these approaches, using in the first case a refractory backbone of biaryl linkages (i.e., poly(phenylenes)), and in the second case a backbone having the major linkage type known to exist in lignins and presumed to be at least partially retained in low-rank coals. In Quarterly Report No. 5, we discussed the difficulties in the first approach and the progress made on the second. 
We have continued in the sixth and seventh quarter to focus on the second approach, involving synthesis of polymers connected by $-\mathrm{CH}_{2} \mathrm{CH}_{2} \mathrm{O}$ - linkages.

The O-C-C " $\beta$-ether" connection between adjacent aromatic rings is the most abundant linkage in lignins, from both angiosperm and gymnosperm sources. In the absence of evidence to the contrary, we have begun by assuming that some significant fraction of these linkages survive into the low-rank coals. If these linkages are important in lignites and subbituminous coals, they provide a very interesting situation. The $\beta$-ether linkage is known (8) to be quite labile, via a free radical chain reaction, under coal liquefaction conditions. In its simplest form, in phenylphenethyl ether $\left(\mathrm{C}_{6} \mathrm{H}_{5}-\mathrm{O}-\mathrm{CH}_{2}-\mathrm{CH}_{2}-\mathrm{C}_{6} \mathrm{H}_{5}\right)$, the $\beta$-ether linkage has a half life at $400^{\circ} \mathrm{C}$ of 120 minutes, forming styrene and phenol. (9) Thus one might speculate that if lignite were composed substantially of such linkages, it would simply fall to pieces under liquefaction conditions - unless retrograde reactions were very facile. Indeed, in the previous contract, we found that two different polymers presumably consisting largely of the $\beta$-ether linkage showed both facile cleavage and extensive crosslinking. However, this observation was clouded by the fact that side reactions could not readily be eliminated in the polymer synthesis (using mercuric trifluoracetate of 4-allylphenol and eugenol (2-methoxy-4-allylphenol)), and we were never able to obtain polymers that gave the correct elemental analysis. For this reason, more extensive study and interpretation of those earlier polymer preparations was judged to be premature.

\section{WORK PERFORMED}

\section{Preparation of the $-\left[\mathrm{C}_{6} \mathrm{H}_{3}(\mathrm{O}-\mathrm{Me}) \mathrm{CH}_{2} \mathrm{CH}_{2}-\mathrm{O}-\right]_{n}-$ Polymer}

In October we prepared two small test batches of the methoxy substituted model polymer $\left(-\left[\mathrm{C}_{6} \mathrm{H}_{3}(\mathrm{O}-\mathrm{OMe}) \mathrm{CH}_{2} \mathrm{CH}_{2}-\mathrm{O}-\right]_{n}-\right)$, using reaction times of 3 and 5 days. Both of these polymers were largely soluble in $\mathrm{CDCl}_{3}$, though they were surprisingly somewhat less soluble in THF. We have obtained the ${ }^{1} \mathrm{H}$ and ${ }^{13} \mathrm{C}$ solution phase NMR spectra; these spectra show the polymers to have $<5 \%$ impurities.

\section{Pyrolysis-FIMS of the -C-C-O- polymers}

General Features and Mechanistic Expectations. The pyrolysis-FI mass spectrum for the threeday preparation of $-\left[\mathrm{C}_{6} \mathrm{H}_{3}(\mathrm{O}-\mathrm{OMe}) \mathrm{CH}_{2} \mathrm{CH}_{2}-\mathrm{O}-\right]_{n}-$, shown in Figure IV-1, is similar in general terms to those for the $-\left[\mathrm{PhCH}_{2} \mathrm{CH}_{2}-\mathrm{O}_{n}\right.$ - polymer preparations shown in the last quarterly report (reproduced here as Figure IV-2). However, there are interesting differences that indicate variations in pyrolytic behavior. All the spectra show a series of oligomers (more precisely, a series of oligomers with a double bond in one of the ethylene groups, presumably preferentially the terminal $-\mathrm{CH}_{2}=\mathrm{CH}_{2}$ grouping) that would be expected from simple non-reductive cleavage. In all 


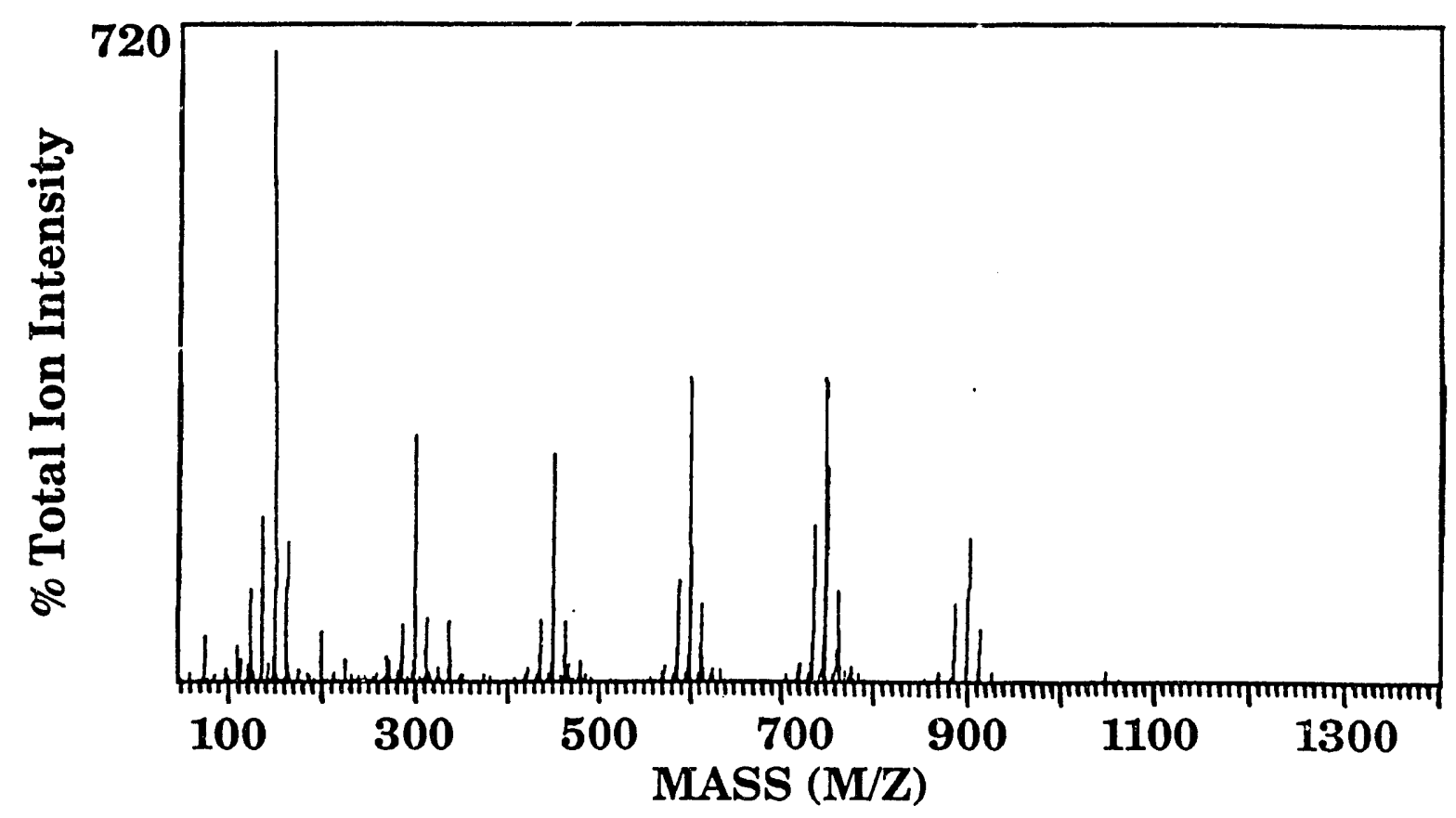

Figure IV-1. Pyrolysis-FI Mass Spectrum for $-\left[\mathrm{C}_{6} \mathrm{H}_{3}(\mathrm{o}-\mathrm{OMe}) \mathrm{CH}_{2} \mathrm{CH}_{2}-\mathrm{O}-\right]_{\mathrm{n}}-\mathrm{Polymer}$.

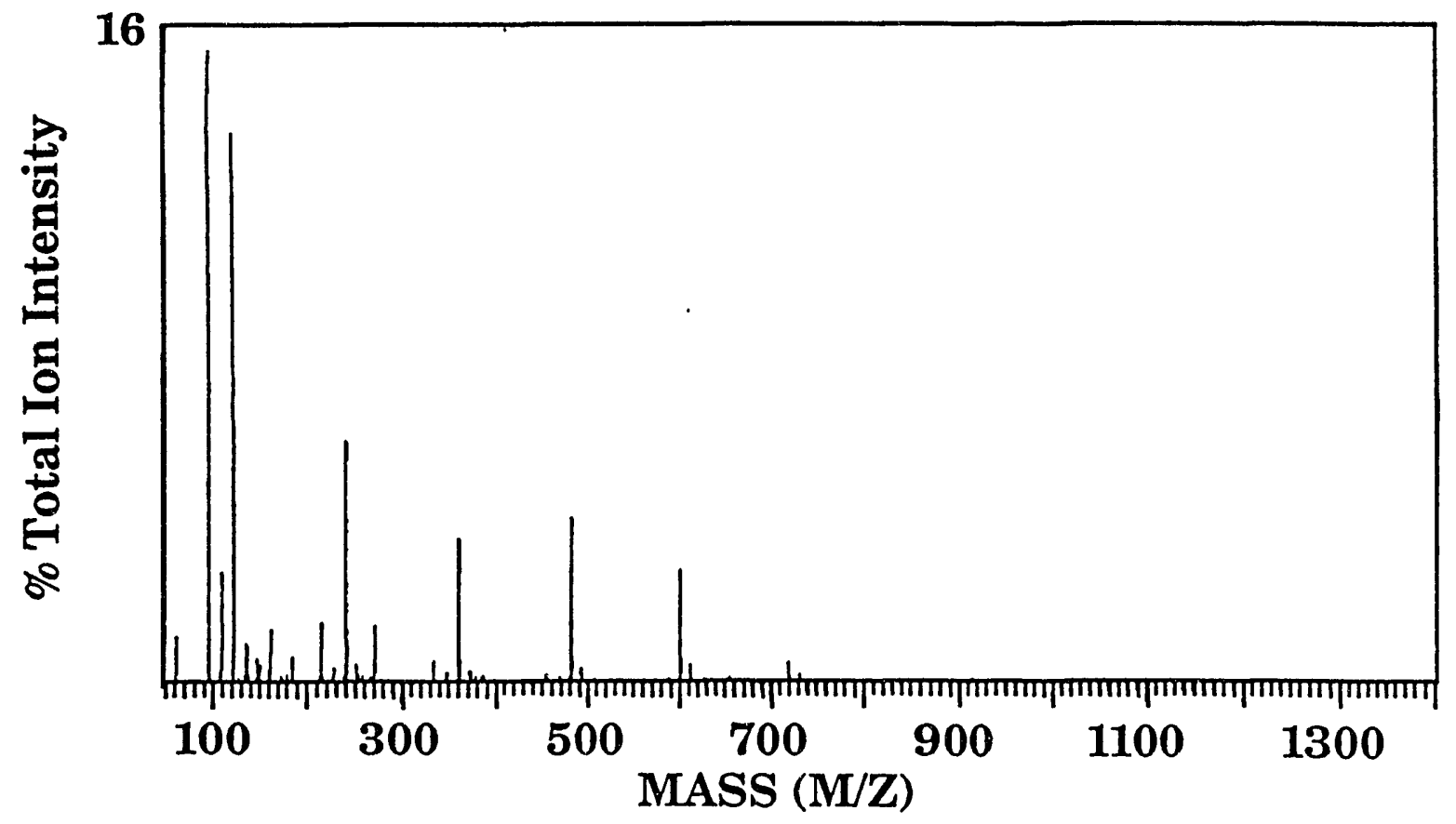

Figure IV-2. Pyrolysis-FI Mass Spectrum for - $\left[\mathrm{PhCH}_{2} \mathrm{CH}_{2}-\mathrm{O}-\right]_{\mathrm{n}}-\mathrm{Polymer}$. 
cases, a dominance of monomer over dimer, trimer, etc., from the onset of decomposition through its completion indicates that the linkages are being cleaved in a coordinated, or unzipping manner. We can qualitatively rationalize this unzipping by postulating that the radical-chain $\mathrm{H}$-abstraction - $\beta$-scission processes that account for the decomposition of monomeric -C-C-O- linked structures would here lead to the chain transfer $\mathrm{H}$-abstraction reactions occurring preferentially on the end unit. This sequence is illustrated in Scheme 1.

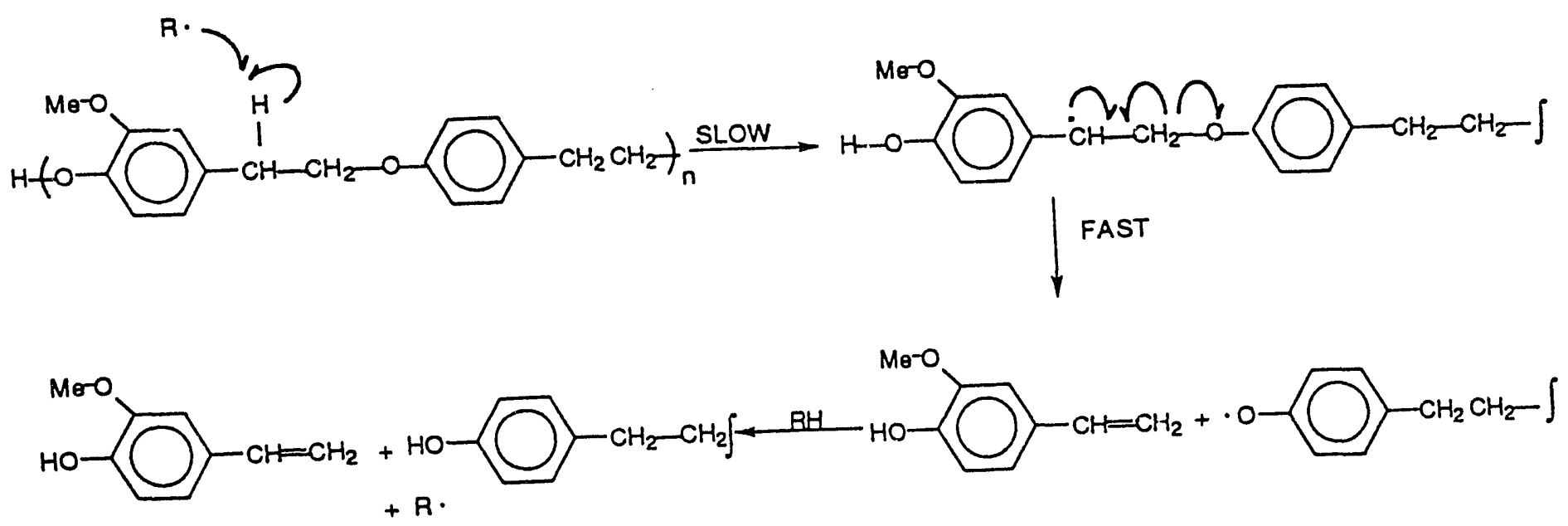

Scheme 1. Possible radical-chain unzipping sequence for -C-C-O-polymers.

Autoacceleratory Character of the Decomposition. In view of the probable coiled configurations of these linear polymers, and thus the likely proximity of many interior chain positions, rationalization of the pronounced unzipping tendency simply in terms of a radical chain mechanism does not appear really satisfactory. In any case, central bond cleavage is clearly a chain or an autocatalytic process, such that once cleavage begins at about $300^{\circ} \mathrm{C}$, it proceeds progressively more rapidly, leading to essentially complete volatilization by $350^{\circ} \mathrm{C}$. This behavior is illustrated by the vacuum "evaporation" curves shown in Figures IV-3 and IV-4, depicting the temperature dependence of volatiles formation observed during acquisition of the spectra in Figures IV-1 and IV-2, respectively. While both curves are very steep after the threshold is passed at about $300^{\circ} \mathrm{C}$, the curve in Figure IV-3 for the- $\left[\mathrm{C}_{6} \mathrm{H}_{3}(0-\mathrm{OMe}) \mathrm{CH}_{2} \mathrm{CH}_{2}-\mathrm{O}-\right]_{n}-$ polymer is drastically "overhung." In other words, the ion current rose so quickly once the decomposition threshold was passed (at $\sim 300^{\circ} \mathrm{C}$ ) that the probe temperature had to be decreased substantially to keep from exceeding the ion counting capability of the instrument. We note that the threshold itself actually does not occur at a significantly lower temperature than for the $-\left[\mathrm{PhCH}_{2} \mathrm{CH}_{2}-\mathrm{O}-\right]_{n}$ polymer: in both cases the threshold appears between 300 and $350^{\circ} \mathrm{C}$. However, once decomposition begins, it proceeds much more rapidly with the methoxy-substituted polymer. That is, there is a much more pronounced autocatalytic behavior with that material. 


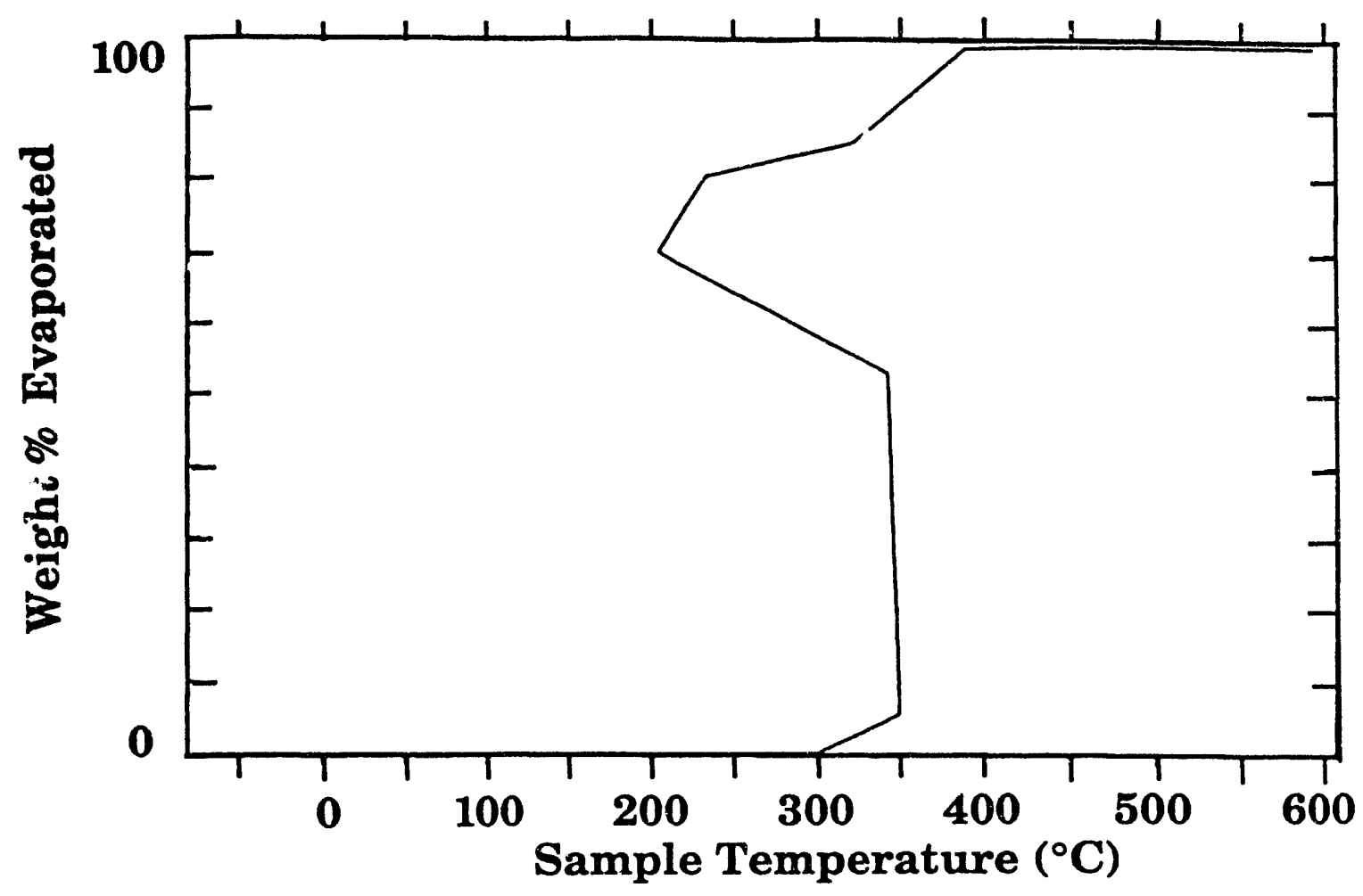

Figure IV-3. Vacuum Evaporation Curve for $-\left[\mathrm{C}_{6} \mathrm{H}_{3}(\mathrm{o}-\mathrm{OMe}) \mathrm{CH}_{2} \mathrm{CH}_{2}-\mathrm{O}-\right]_{\mathrm{n}}-\mathrm{Polymer}$.

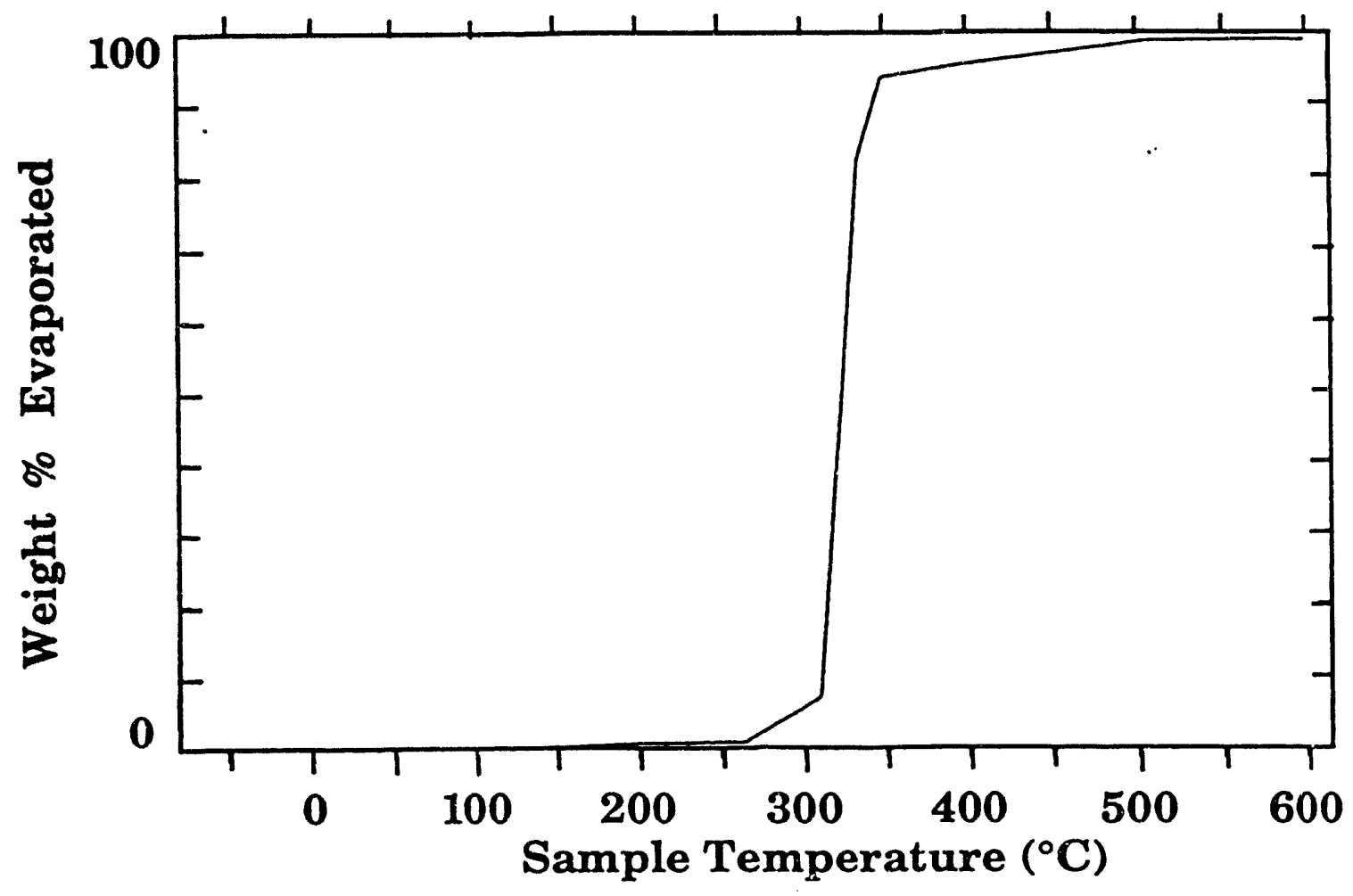

Figure IV-4. Vacuum Evaporation Curve for-[ $\left.\mathrm{PhCH}_{2} \mathrm{CH}_{2}-\mathrm{O}-\right]_{n}-\mathrm{Polymer}$. 
Our current thinking is that this striking autocatalysis may be indicaling a new reaction pathway. The reasoning is as follows, proceeding in two steps from phenylphenethyl ether $\left(\mathrm{PhCH}_{2} \mathrm{CH}_{2}-\mathrm{O}\right.$ Ph, "PPE"), the simplest "dimer" unit one can consider a prototype for these $\beta$-ether lignin-like polymers. This prototype has been studied by several groups in recent years, notably Klein and Virk (8), Britt and Buchanan, (9) and Gilbert and Gajewksi (10). This work has been authoritatively reviewed by Poutsma (11). The changes in bond strength one expects in going from PPE to the simple -C-C-O- polymer and then to the methoxy-substituted -C-C-O-polymer are shown in Table IV-1, together with the half-lives for decomposition. The bond strength estimates are made, in large part, on the basis of recent kinetic studies published by Stein for pyrolysis of anisole derivatives (12).

Table IV-1

Bond Strengths and Decomposition Rates for -C-C-O- Linked Aromatic Ring Systems

\begin{tabular}{|c|c|c|c|c|}
\hline \multirow[t]{2}{*}{ STRUCTURE } & \multirow{2}{*}{$\begin{array}{c}\mathrm{BDE}^{\mathrm{a}} \\
\mathrm{CH}_{2}-\mathrm{O}\end{array}$} & \multirow{2}{*}{$\begin{array}{c}\text { BDE } \\
{ }^{\mathrm{a} A r C(H)-H} \\
\mathrm{kcal} / \mathrm{mol}\end{array}$} & \multicolumn{2}{|c|}{$\begin{array}{c}t_{1 / 2} \text { Obs } \\
\text { (min) }\end{array}$} \\
\hline & & & $300^{\circ} \mathrm{C}$ & $350^{\circ} \mathrm{C}$ \\
\hline $\mathrm{PinCH}_{2} \mathrm{CH}_{2} \mathrm{OPh}$ & 60 & 85 & $4 \times 10^{4}$ & 2500 \\
\hline$-\left[\mathrm{OPhCH}_{2} \mathrm{CH}_{2} \mathrm{OPhCH}_{2} \mathrm{CH}_{2}\right]_{n}-$ & 59.6 & $\sim 83$ & $\begin{array}{c}5^{b} \\
\left(325^{\circ} \mathrm{C}\right)\end{array}$ & \\
\hline$\left.-\mathrm{C}_{6} \mathrm{H}_{3}(\mathrm{O}-\mathrm{OMe}) \mathrm{CH}_{2} \mathrm{CH}_{2}-\mathrm{O}-\right]_{n}-$ & 5.7 & $\sim 83$ & $\begin{array}{c}<^{b} \\
\left(325^{\circ} \mathrm{C}\right)\end{array}$ & \\
\hline
\end{tabular}

a. Estimates based upon data and derived values in references 5 and 6 . Because the differences are small, values have not been rounded to nearest kcal; even though absolute accuracy for any given estimate is probably only 1-2 kcalimol, the relative accuracy should be substantially better.

b. Values taken from vacuum vaporization curves, based on fraction vaporized during the $300^{\circ}$ to $350^{\circ} \mathrm{C}$ interval.

As reviewed by Poutsma, (11) the data for PPE indicate an $\mathrm{H}$-abstraction - $\beta$-scission radical-chain decomposition that is initiated by $\mathrm{CH}_{2}-\mathrm{O}$ bond homolysis, and in which the $\mathrm{H}$-abstraction chaintransfer step is the slowest of the two propagation steps, as shown above in Scheme 1. Comparing first the behavior of the simple $-\left[\mathrm{PhCH}_{2} \mathrm{CH}_{2}-\mathrm{O}-\right]_{n}-$ polymer with PPE, we see that at $300^{\circ} \mathrm{C}$, where $2.3 \mathrm{RT}=2.62$ (in $\mathrm{kcal} / \mathrm{mol}$ units), and therefore where every $\sim 2.6 \mathrm{kcal} / \mathrm{mol}$ decrease in activation energy results in a factor of 10 in rate increase, there would be less than a two-fold increase in initiation rate and no more than a six-fold increase in propagation resulting from the 2 $\mathrm{kcal} / \mathrm{mol}$ decrease in the enthalpic requirement of the $\mathrm{H}$-abstraction step. Together these 
assuming similar termination rates, would lead one to expect an about an order of an order of magnitude increase in overall rate. However, the observed rate went up by more than a factor of 500.

Moving to tive $-\left[\mathrm{C}_{6} \mathrm{H}_{3}(0-\mathrm{OMe}) \mathrm{CH}_{2} \mathrm{CH}_{2}-\mathrm{O}-\right]_{n}-$ polymer, we see that a $\sim \mathrm{kcal} / \mathrm{mol}$ decrease in $\mathrm{CH}_{2}-$ $\mathrm{O}$ bond strength should increase the rate of initiation by a factor of about ten as compared to the $-\left[\mathrm{PhCH}_{2} \mathrm{CH}_{2}-\mathrm{O}-\right]_{n}-$ polymer, but that there stivuld be little further effect on the $\mathrm{H}$-abstraction propagation step, because the added methoxy sroup is meta- to the $-\mathrm{CH}_{2}-$ group. (The $\mathrm{CH}_{2}-\mathrm{O} \beta-$ scission will be accelerated by ortho-methoxy substitution, but in the decomposition of $\beta$-phenethyl ether itself, the $\beta$-scission has been shown (11) to be, by a substantial margin, to not be the ratelimiting propagation step. Therefore, a decrease in $\mathrm{CH}_{2}-\mathrm{O}$ bond strength should have little impact on the overall propagsition rate.) Faster initiation without faster propagation should tend to lower the onset temperature but decrease the steepness of the vaporization curve in Figure IV-3. Since this clearly is not what happened with the methoxy polymer as compared with the simple $-\left[\mathrm{PhCH}_{2} \mathrm{CH}_{2}-\mathrm{O}-\right]_{n}$ - polymer, it appears that a new mechanism may be intervening as this system is made polymeric and progressively more lignin-like.

This conclusion, of course, is at this stage highly speculative; however, it is consistent with the fact that the bond cleavage lifetimes observed for both polymers are substantially shorter than those reported for $\beta$-phenylphenethyl ether ( $\mathrm{Ph}-\mathrm{O}-\mathrm{CH}_{2} \mathrm{CH}_{2} \mathrm{Ph}$ ). To summarize, the terminal hydroxy group, as it apparently does with lignins, seems to activate the adjacent -C-C-O- linkage to an extent not readily explained by the radical-chain chemistry considered sufficient for the simple ether itself. Furthermore, the addition of a methoxy group ortho- to the O-Ar attachment additionally enhances the reaction rate in a way that is not readily explained by the expected radical-chain chemistry.

Generation of Satellite Peaks from Loss and Addition of Methyl Groups. Another prominent difference between the Py-FIMS of the unsubstituted and methoxy-substituted -C-C-O-polymers lies in the different levels of satellites they generate at $\pm n(14)$ mass units from each of the main oligomer peaks. This difference can easily be seen by comparison of the spectrum in Figure IV-1 for $-\left[\mathrm{C}_{6} \mathrm{H}_{3}(\mathrm{O}-\mathrm{OMe}) \mathrm{CH}_{2} \mathrm{CH}_{2}-\mathrm{O}-\right]_{n}$ - with that in Figure IV-2 for the- $\left[\mathrm{PhCH}_{2} \mathrm{CH}_{2}-\mathrm{O}\right.$ $l_{n}$ polymer. Qualitatively it is not surprising that the satellite peaks at -14 and -28 are more prominent with the methoxy-substituted polymer, given that the ArO-Me bond is moderately weak, but the size of these satellites is a quantitative surprise. The -14 satellites could be formed by simple homolysis of one of the ArO-Me bonds in the methoxy polymer, but since literature data suggest $\mathrm{O}-\mathrm{Me}$ bond in the $\mathrm{OH}$-terminated aromatic ring (est. $\mathrm{BDE}=\sim 60 \mathrm{kcal} / \mathrm{mol}$ ) should exhibit a homolyis half-life of about 20,000 minutes at $300^{\circ} \mathrm{C}$ and 400 minutes at $350^{\circ} \mathrm{C}$, the roughly 12 minutes required to go from 300 to $350^{\circ} \mathrm{C}$ and generate the volatiles would appear to be insufficient 
to allow roughly one out of every five monomer units to have lost a methyl group. Therefore, we tentatively conclude that the loss of methyl groups is somehow coupled to cleavage of the central linkage.

The rather small variation in intensity of the satellite peaks relative to their respective "parent" oligomer peaks shown in Figure IV-1 is something we do expect to see. Since in all interior units of any oligomer, the O-Me bond strength is about $3 \mathrm{kcal} / \mathrm{mol}$ higher (with 300 - and $400^{\circ} \mathrm{C}$ - half-lives of 300,000 and 4,000 minutes, respectively), we do expect, in oligomer units below $n=\sim 10$, to have most of the O-Me cleavage occur on the terminal ring system. In accord with this expectation, the intensity of satellites at - 14 Daltons in Figure IV-1 increases from roughly $20 \%$ of the oligomer parent in the monomer to only about $40 \%$ of the parent in the hexamer.

The additional implication of observing rather little methyl loss except from the terminal unit is that notwithstanding its moderately weak bond, most of the O-Me aralkyl ether bonds can, under appropriate conversion condtions, perhaps remain intact long enough to provide crosslink protection for the dihydroxy arumatic units. This presumably explains why there was $100 \%$ vaporization during Py-FiMS of the $-\left[\mathrm{C}_{6} \mathrm{H}_{3}(\mathrm{O}-\mathrm{OMe}) \mathrm{CH}_{2} \mathrm{CH}_{2}-\mathrm{O}-\right]_{n}-$ polymer, but the presumption needs to be tested (see below).

Extent of Cleavage by Hydrodealkylation. One other very noticeable difference between the $\left[\mathrm{PhCH}_{2} \mathrm{CH}_{2}-\mathrm{O}\right]_{n}-$ and $-\left[\mathrm{C}_{6} \mathrm{H} 3(0-\mathrm{OMe}) \mathrm{CH}_{2} \mathrm{CH}_{2}-\mathrm{O}-\right]_{n}-$ polymers is the much larger intensity of the peak corresponding to dealkylated monomer (i.e, to phenol in the former case, and methoxy phenol, or guaiacol, in the latter case) in the polymer not having the methoxy substitution. Thus the $\mathrm{m} / \mathrm{z} 94$ peak in Figure IV-2 is much larger than the $\mathrm{m} / \mathrm{z} 124$ peak in Figure IV-1. As we have previously noted, formation of phenol (or guaiacol) requires not only cleavage of the $\mathrm{C}-\mathrm{O}$ linkages on either side of a given aromatic ring (a non-hydrogenative, or non-reductive, cleavage), but also a hydrodealkylation or hydrogenolysis to remove the two-carbon chain, as shown below.

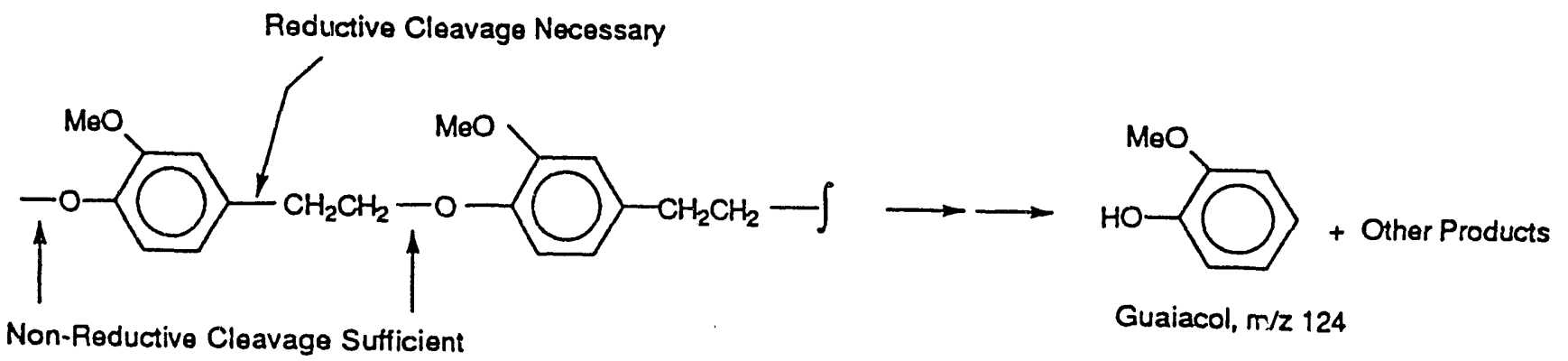

Scheme 2. Required bond cleavages to form dealkylated monomer. 
The ultimate origin of the hydrogen necessary to form the dealkylated or otherwise reduced oligomers is not evident in the FI mass spectrum of Figure IV-2. That is, the sum of hydrodealkylated and reduced oligomers, at least up to $n=3$, is about ten times the sum of oxidized oligomers. Presumably the necessary additional hydrogen has come from the $20 \%$ of the - $\left[\mathrm{PhCH}_{2} \mathrm{CH}_{2} \mathrm{O}_{n}\right.$ - that failed to volatilize under the pyrolysis-FIMS conditions. Such disproportionation phenomena are quite common in pyrolytic processes, such as the hydrotreating of petroleum- or coal-derived resids, although the detailed mechanisms are generally unclear (13).

In the case of the $-\left[\mathrm{C}_{6} \mathrm{H}_{3}(\mathrm{O}-\mathrm{OMe}) \mathrm{CH}_{2} \mathrm{CH}_{2}-\mathrm{O}-\right]_{n}-$ polymer, there is much less hydrodealkylation. As can be seen in Figure IV-1, the ratio of guaiacol to $\mathrm{HOC}_{6} \mathrm{H}_{3}(0-\mathrm{OMe})-\mathrm{Ch}=\mathrm{CH}_{2}$ is only about onetenth of $\left(0.14\right.$ vs 1.2) the ratio of phenol to $\mathrm{HOPh}-\mathrm{Ch}=\mathrm{CH}_{2}$ from $-\left[\mathrm{PhCH}_{2} \mathrm{CH}_{2}-\mathrm{O}\right]_{n}-$ (Figure IV2). We do not yet know whether this is because the methoxy substitution actually slows hydrogenolysis, or simply because it speeds up the competing cleavage of the O-C bonds in the main linkages. It is noteworthy that the $-\left[\mathrm{C}_{6} \mathrm{H}_{3}(0-\mathrm{OMe}) \mathrm{CH}_{2} \mathrm{CH}_{2}-\mathrm{O}\right]_{n}-$ polymer whose Py-FIMS spectrum is shown in Figure IV-1, was $100 \%$ (i.e., $97 \pm 3 \%$ ) volatile. That is, there was very little hydrogen-poor char whose formation would have freed up the hydrogen necessary for widespread hydrogenolysis. This leads one to ask, once again, (13) the question, "To what extent (i.e., with what inevitability) is hydrogenolysis, which one wants, driven by crosslinking, which one does not want (at least in the coal liquefaction, heavy-oil processing contexts)?" In any case, a similar observation, namely that free phenolic groups on polymer models results in both more crosslining and in more indiscriminate bond scission than results from their methylated analogs, can be drawn from pyrolysis-FIMS data for other polymer types published several years ago by Solomon and Squire (14).

Implications of -C-C-O- Polymer Decomposition Behavior. To summarize the thermal decomposition behavior, both the $\left[\mathrm{PhCH}_{2} \mathrm{CH}_{2}-\mathrm{O}_{n}\right.$ - polymer and its methoxylated analog, $-\left[\mathrm{C}_{6} \mathrm{H}_{3}(\mathrm{O}-\mathrm{OMe}) \mathrm{CH}_{2} \mathrm{CH}_{2}-\mathrm{O}-\right]_{n}-$, undergo rapid coordinated linkage cleavage, or unzipping, in the 300 to $350^{\circ} \mathrm{C}$ temperature region, yielding $80 \%$ or more volatile material under the temperatureprogrammed vacuum pyrolysis conditions of FIMS analysis. This general behavior was expected, inasmuch as the simplest element of these polymers, phenylphenethyl ether undergoes fairly rapid central bond cleavage in a radical-chain $\mathrm{H}$-abstraction- $\beta$-scission process. However, the facility and pronounced autocatalytic depolymerization of the two new polymers was quantitatively unexpected. By the same token, the crosslinking, or retrograde reaction, has been rather less than we expected (and less than we observed last year with a more impure and potentially precrosslinked sample of the $-\left[\mathrm{C}_{6} \mathrm{H}_{3}(0-\mathrm{OMe}) \mathrm{CH}_{2} \mathrm{CH}_{2}-\mathrm{O}-\right]_{n}-$ polymer). The surprising facility of depolymerization of the remnants of lignin most likely to be found in low-rank coals provides some tentative conclusions and raises further questions relevant to the liquefaction of low-rank coals. First, if crosslinking (in low-rank coals) is to be competitive with this type of depolymerization, the crosslinking must be exceedingly facile. Second, it follows then that none of the rather limited 
crosslinking behavior we observed in our studies with various aromatic and aliphatic (and at least arguably coal-related) carboxylic acids was facile enough to support the long-standing speculation that decarboxylation instigated crosslinking is the major cause of retrograde reactions during preheating and/or liquefaction. Third, these results throw attention regarding the issue of retrograde reactions back to phenolic $-\mathrm{OH}$ as the major site/source of crosslinking and further emphasize the importance of comparing the conversion behavior of the $-\left[\mathrm{C}_{6} \mathrm{H}_{3}(0-\mathrm{OMe}) \mathrm{CH}_{2} \mathrm{CH}_{2}\right.$ O- $]_{n}$ - polymer with the unmethylated analog $-\left[\mathrm{C}_{6} \mathrm{H}_{3}(\mathrm{O}-\mathrm{OH}) \mathrm{CH}_{2} \mathrm{CH}_{2}-\mathrm{O}-\right]_{n}-$. Fourth, the unexpected facility and autocatalytic nature of the $-\left[\mathrm{C}_{6} \mathrm{H}_{3}(\mathrm{O}-\mathrm{OMe}) \mathrm{CH}_{2} \mathrm{CH}_{2}-\mathrm{O}-\right]_{n}-$ depolymerization, which cannot readily be explained by simple free radical pathways, raises the question of whether electron-transfer may be important in the decomposition of these model coal polymers, and if so, whether explicit attempts to exploit such chemistry might be practical.

\section{Demethylation of the $-\left[\mathrm{C}_{6} \mathrm{H}_{3}(\mathrm{O}-\mathrm{Me})-\mathrm{O}-\mathrm{CH}_{2} \mathrm{CH}_{2}\right]_{n}-$ Polymer}

The complete lack of crosslinking observed under Py-FIMS conditions for this polymer, if anything, increases the relevance comparing its behavior with that of the analog containing free $-\mathrm{OH}$ rather than -OMe groups. Four different reactions for effecting the selective cleavage of the ArO-Me bond in the presence of the ArO- $\mathrm{CH}_{2}$ bond were studied. The first reaction is the method of Harrison, (15) which involves heating of the polymer with Lil in collidine at $185^{\circ} \mathrm{C}$ for about $10 \mathrm{~h}$. During the reaction the sample darkened considerably, although after aqueous work up, the solid isolated was only light brown, and was partially soluble in $\mathrm{CDCl}_{3}$. The ${ }^{1} \mathrm{H} \mathrm{NMR}$ of the $\mathrm{CDCl}_{3}$ solution was essentially identical to that of the starting material, except that the peak due to the methoxy group now had the same area as that due to the $0-\mathrm{CH}_{2}$ peak. Also, there was a small broad peak at 5.5 ppm, most likely due to free phenolic. These data are consistent with cleavage of about a third of the methyls in the starting polymer.

The second reaction was a variation on the first one. It involved heating the polymer with $\mathrm{NaCN}$ in DMSO at $185^{\circ} \mathrm{C}$. (16) Unfortunately, the product from this reaction was only slightly soluble in DMSO. The soluble portion was found to be the unconverted starting material. The rest of the product was dark and intractable. We also tried the method of McKervey (17) using lithium aluminum hydride in benzene. However, this procedure was not successful with our polymer.

Finally, we attempted the reaction with iodotrimethylisilane. This reagent is potent enough to cleave the ArO- $\mathrm{CH}_{2}$ linkages as well, and we hoped that be carefully controlling the conditions, we might achieve the desired selectivity. Tests in small scale experiments in NMR tube showed that the cleavage of $\mathrm{O}-\mathrm{CH}_{3}$ was about three times faster than that of the $\mathrm{O}-\mathrm{CH}_{2}$ linkage. We are encouraged by these early results and will pursue this reaction in the next quarter. 


\section{TASK 4 - DATA INTEGRATION AND REPORTING}

Work was completed on the ACS Denver paper, titled "The Effects of Moisture and Cations on liquefaction of Low Rank Coals." A copy is included as Appendix A. The conclusions from this paper are as follows:

- The tar yields and liquefaction yields are reduced for all three cations tested $\left(\mathrm{K}^{+}\right.$, $\mathrm{Ca}^{++}, \mathrm{Ba}^{++}$) and are lower for the fully exchanged coals. The ability of cations to act as initial crosslinks is an important aspect of their role in retrogressive reactions.

- The previously observed correlation between pyrolysis tar and liquefaction yields for coals and modified coals appears to hold for the vacuum-dried cation-exchanged coals, but not always for the re-moisturized coals.

- The total evolution of $\mathrm{CO}_{2}$ and $\mathrm{CO}$ from pyrolysis is changed significantly by cation-exchange. However, only in the case of $\mathrm{CO}$ does the evolution profile change significantly.

- After careful demineralization, a calcium form Zap or Wyodak coal can be prepared at $\mathrm{pH}=8$, which is similar to the raw coal with regard to pyrolysis and liquefaction behavior.

- At $\mathrm{pH}=8$, cations are most likely to be coordinating multiple oxygen functionalities around themselves through electrostatic type interactions, which diminishes the importance of valency.

- Some of the moisture in a coal is associated with the cations. The moisture content has a larger role in liquefaction than in pyrolysis because it is present for a longer period of time.

In addition, three abstracts were prepared for the International Conference on Coal Science (Banff, Alberta, CANADA, September 12-17, 1993) based on the work done under this project. The first is titled "The Role of Cations in Retrogressive Reactions During Pyrolysis and Liquefaction," which concerns the work done on coals and modified coals. The second is titled "Application of a Spectral Deconvolution Technique to Coal FT-IR Spectra," which concerns the use of FT-IR methods for measurement of carboxyl and hydroxyl functions. The third paper is titled "Pyrolysis Pathways and Kinetics of Polymeric Models for Low-Rank Coals" which focuses on the thermal decomposition chemistry of the $\beta$-ether-linked lignin model polymers. Copies of the three abstracts are included in Appendix B. 


\section{PLANS FOR EIGHTH QUARTER}

\section{Task 2. Studies with Coals and Modified Coals}

The demineralized and methylated Zap lignite sample have been prepared and sent to Advanced Fuel Research for liquefaction and TG-FTIR studies. SRI has retained a portion (4 grams out of 14.2 grams), and it still possible that they will subject this portion to partial dealkylation. However, even though the objective here would be for example to hydrolyze the methyl esters without cleaving the methyl ethers, the subtleties involved in cleaving one type of O-Me linkage without cleaving another (see Task 3), together with limitations in the remaining time and funds, could prevent us from producing a partially methylated Zap sample whose liquefaction behavior could be reliably interpreted.

Work will be completed on the use of the FT-IR methods for measuring carboxyl and phenolic functions.

\section{Task 3 - Studies with Polymeric Model Systems}

Small portions of the $-\left[\mathrm{C}_{6} \mathrm{H}_{3}(\mathrm{O}-\mathrm{OMe}) \mathrm{CH}_{2} \mathrm{CH}_{2}-\mathrm{O}-\right]_{n}-$ polymer will be subjected to further variations of ether cleavage conditions to see if partial (or complete) de-methylation can be accomplished with only very little cleavage of the -C-C-O- linkage. This would then provide two (or more) polymer samples of the same or similar molecular weight with varying percentages of "protected" hydroxy groups, whose crosslinking behavior could then be directly compared. We do not yet know how successfil this attempt will be, since we are trying to find conditions under which one alkyl-aryl ether (ArO-Me) is cleaved, while another $\left(\mathrm{ArO}-\mathrm{CH}_{2} \mathrm{CH}_{2}-\right.$ ) is essentially untouched, in order that varying molecular weight distributions between the methylated and de-methylated polymers will not grossly distort the results.

\section{Task 4 - Data Integration and Reporting}

Work will be completed on the use of the FG-DVC liquefaction model to simulate results for modified coals. 


\section{REFERENCES}

1. Jackson, R.S., Griffiths, P.R., Anal. Chem., 63, 2557 (1991).

2. Pierce, J.A., Jackson, R.S., Van Every, K.W., Griffiths, P.R., Anal. Chem., 62, 447, (1990).

3. Friesen, W.I., Michaelin, K.H., Appl. Spec., 45, 50 (1991).

4. Starsinic, M., Otake, Y., Walker, Jr., P.L., Painter, P.C., Fuel, 63, 1002 (1984).

5. Solomon, P.R., Hamblen, D.G., Carangelo, R.M., ACS Symposium Series, 205, 4, 77 (1982).

6. Solomon, P.R., Carangelo, R.M., Fuel, 61, 663, (1982) and Fuel, 67, 949, (1987).

7. Serio, M.A., Kroo, E., Teng., H., Solomon, P.R., "The Effects of Moisture and Cations on Liquefaction of Low Rank Coals," ACS Div. of Fuel Chem. Prepr. 38(2), 577 (1993).

8. Klein, M,T., Virk, P.S., Ind. Eng. Chem., Fudam, 22, 35 (1983).

9. Britt, P., Buchanan, A.C., Energy and Fuels, 6, XXX, (1992).

10. Gilbert, K.E., Gajewski, J.J., J. Org. Chem., 47, 4899 (1982).

11. Poutsma, M.L., "A Review of Thermolysis Studies of Model Compounds Relevant to Processing of Coal," Oak Ridge National Laboratory Report, ORNL/TM-10637, (1987).

12. Surynam, M.M., Kafafi, S.A., Stein, S.E., J. Am. Chem. Soc., 11, 4594, (1989).

13. McMillen, D.F., Manion, J.A., Malhotra, R., Am. Chem. Soc. Div. Fuel Chem. Preprints, 37(4), 1636 (1992).

14. Squire, D.R., Solomon, P.R., DiTaranto, M.B., "Synthesis and Study of Polymer Models Representative of Coal Structure - Phase II," Final Report, Gas Research Institute, August, 1985 (1985).

15. Harrison, I.T., J. Chem. Soc. Chem. Commun., 616, (1969).

16. McCarthy, J.R., Moore, J.L., Cregge, R.J., Tet. Lett., 5183 (1978).

17. Carroll, J.F., Kulkowit, S., McKervey, M.A., J. Chem. Soc. Chem. Commun., 507 (1980). 

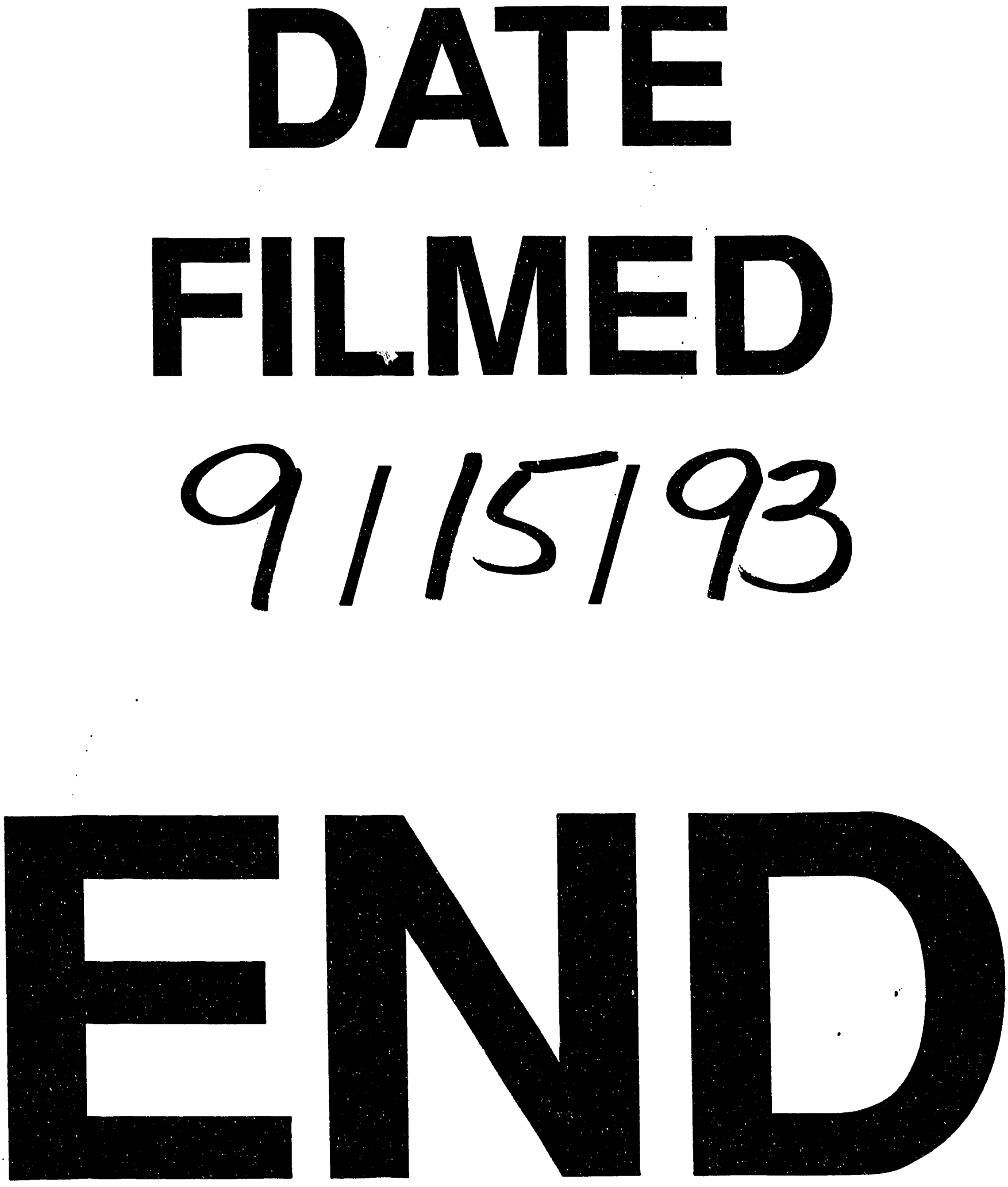
